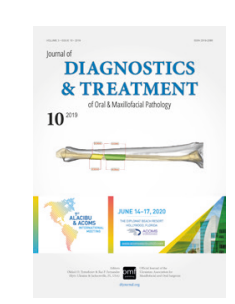

Viewpoint

\title{
Intraoperative Look on Immediate Implant Placement in Anterior Maxilla with Exhibiting Periapical Lesions
}

Sir:

Infection in the site of immediate dental implantation became an invetigation purpose of numerous studies. ${ }^{1-3}$ Conclusions of the prominent reports:

1. Lindeboom et al's study based on fifty patients proved a survival rate of 92 percent for immediately placed implants in periapical infected site versus 100 percent for delayed implants (after a 3-month healing period).

2. Casap et al's results emphasized that 29 from 30 implants (immediately placed into debrided infected sites) were osseointegrated and functional when followed up after twelve to seventy-two months. ${ }^{3}$

3. Chrcanovic et al's systematic review of publications dedicated to analysis of implantation into infected sites showed positive results if meticulous cleaning, socket curettage/ debridement, and chlorhexidine $0.12 \%$ rinse are performed.

An illustrated review of Navaes et al presented a perfect guide for surgery in the infected sites into maxillary bone tissue. ${ }^{5}$ Supported the highlited successful surgical steps ${ }^{5}$ we present a successful implantation (at 7-month follow-up) having: 1) profuse purulent discharge on the day of surgery, 2) lack of sufficient alveolar bone, and 3) with no usage of augmentation materials.

A 59-year-old Caucasian male presented with an unsuccessfully treated periapical lesions of the mobile teeth 1.1 and 2.1 (Fig 1A) and permanent halitosis due to purulent discharge. Two dental implants were placed obtaining primary stability immediatly after removal of teeth 1.1 and 2.1 with periapical lesions (Fig 1B), meticulous curettage, and rinsing by chlorhexidine $0.12 \%$. Surgical step accompanied with a bleeding from a lateral incisive canal (synonyms: neurovascular variation in anterior palate, accessory canal of the anterior maxilla, and lateral incisor canal ${ }^{6}$ located at the palatal aspect of the left central incisor's socket. Figure 2B demonstrates intraoperative stage of temporary crowns' producing. Oral clindamycin was prescribed 1 hour before surgery and continues $600 \mathrm{mg}$ twice daily for 5 days. About 0.12 percent of chlorhexidine rinse twice a day until suture removal was also recommended. ${ }^{7}$ At 7-month follow-up cone-beam computed tomography showed a good bone union near osseintegrated implants.

Performing an immediate implantation into the tooth socket sites with periapical lesions, infection, and alveolar bone dehiscence is possible with a receiving a predictable functional and esthtic outcome in anterior maxilla. Two key factors of success in those cases are 1) thorough debridement of the site prior to placement and 2) primary stability.

Ivan V. Nagorniak ${ }^{a,}$ Kateryna Y. Nagorniak

\footnotetext{
${ }^{\text {a }}$ Oral Surgeon, PhD; Private Dental Practice, Kyiv, Ukraine.

${ }^{\mathrm{b}} \mathrm{PhD}$ Student; Department of Therapeutic Dentistry, Stomatology Institute, NMAPE, Kyiv, Ukraine.

${ }^{*}$ Corresponding author: Private Dental Practice, 6-G Andruschenka Street, Office 6, Kyiv 01135, Ukraine. E-mail: ivan.nagorniak@gmail.com (Ivan Nagorniak)

http://dx.doi.org/10.23999/j.dtomp.2019.10.3.

(C) 2019 OMF Publishing, LLC. This is an open access article under the CC BY license (http://creativecommons.org/licenses/by-nc/4.0/).
} 

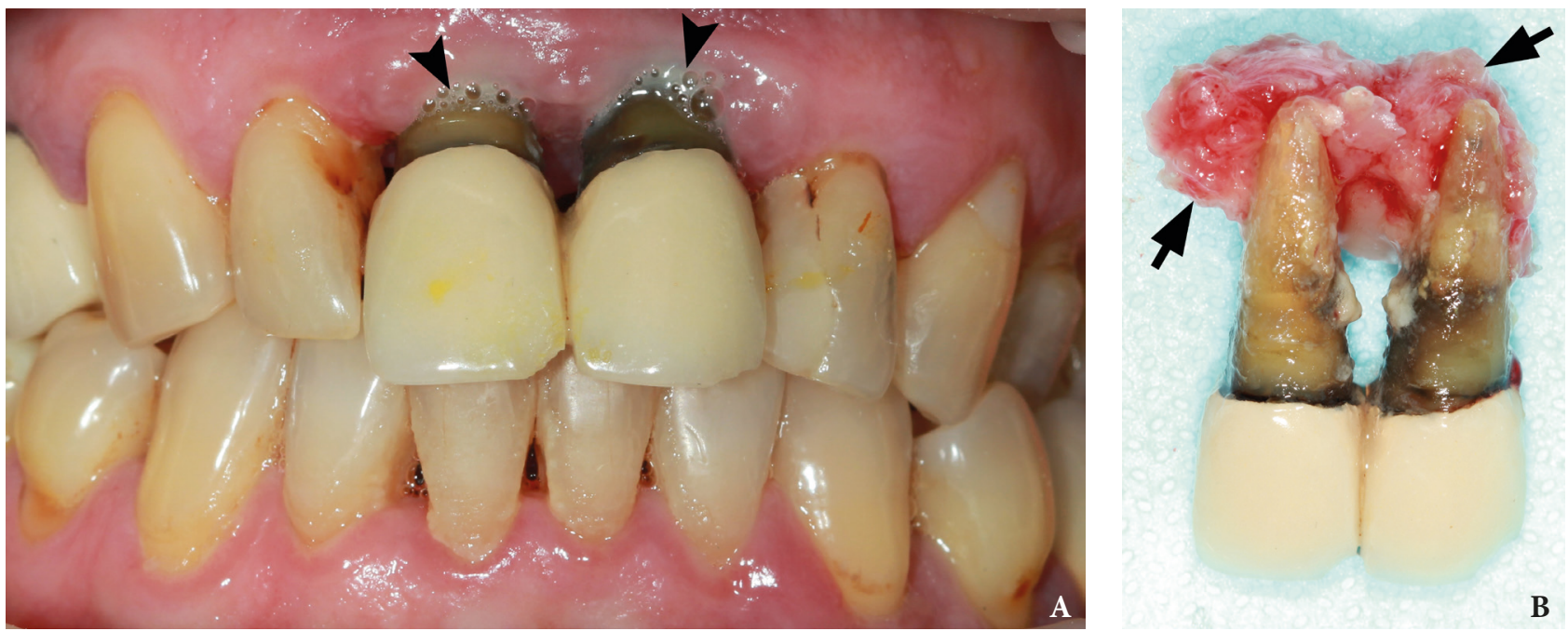

FIGURE 1. (A) Intraoral anterior view with purulent discharge from gingival sulci of the teeth (arrowheads) immediate before teeth extraction and dental implants installation. (B) Extracted teeth 1.1 and 2.1 with attached periapical lesions (arrows).
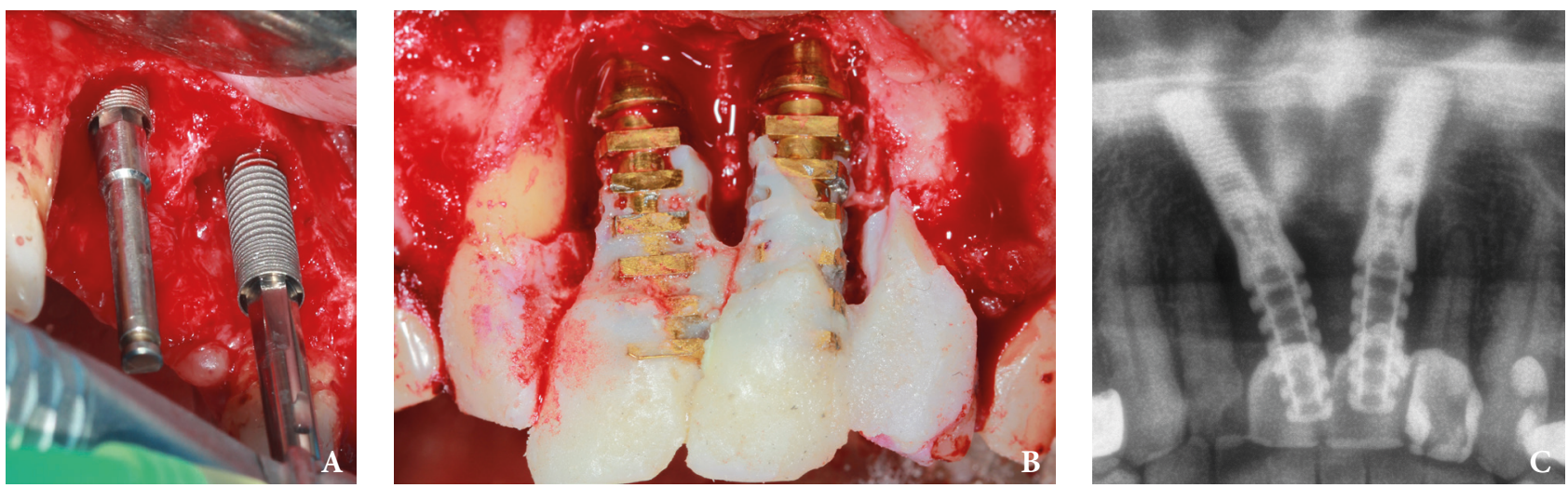

FIGURE 2. Intraoperative view at the stages of dental implants placement $(\mathbf{A})$ and producing of temporary crowns (B). Post-operative cropped panoramic radiography $(\mathbf{C})$.

\section{REFERENCES}

1. Lindeboom JA, Tjiook Y, Kroon FH. Immediate placement of implants in periapical infected sites: a prospective randomized study in 50 patients. Oral Surg Oral Med Oral Pathol Oral Radiol Endod 2006;101:70510. https://doi.org/10.1016/j.tripleo.2005.08.022.

2. Waasdorp JA, Evian CI, Mandracchia M. Immediate placement of implants into infected sites: a systematic review of the literature. J Periodontol 2010;81:801-8. https://doi.org/10.1902/jop.2010.090706.

3. Casap N, Zeltser C, Wexler A, Tarazi E, Zeltser R. Immediate placement of dental implants into debrided infected dentoalveolar sockets. J Oral Maxillofac Surg 2007;65:384-92.

4. Chrcanovic BR, Martins MD, Wennerberg A.
Immediate placement of implants into infected sites: a systematic review. Clin Implant Dent Relat Res 2015;17 Suppl 1:e1-e16. https://doi.org/10.1111/cid.12098.

5. Novaes Jr. AB, Muglia VA, Ramos, UD, Reino DM, Ayub LG. Immediate implants in extraction sockets with periapical lesions: an illustrated review. J Osseointegr 2013;5:45-52. https://doi.org/10.23805/ jo.2013.05.03.02.

6. Nagorniak IV. Clinical appearance of lateral incisive canal. J Diagn Treat Oral Maxillofac Pathol 2019;3:200. https://dx.doi.org/10.23999/j.dtomp.2019.8.4.

7. Surapaneni H, Yalamanchili PS, Basha MH, Potluri S, Elisetti N, Kiran Kumar MV. Antibiotics in dental implants: a review of literature. J Pharm Bioallied Sci 2016;8(Suppl 1):S28-S31. https://dx.doi. org/10.4103/0975-7406.191961. 